\title{
Neurocognitive Dysfunction in Brain Tumor Patients following Radiation Therapy: A Review of Biological Hypotheses, Current Treatment Outcomes, and Novel Therapeutic Strategies Raj Singh, MSII ${ }^{1}$
}

\section{Author Affiliations:}

1. Joan C Edwards School of Medicine, Marshall University, Huntington, West Virginia The author has no financial disclosures to declare and no conflicts of interest to report.

\section{Corresponding Author:}

Raj Singh, MSII

Joan C Edwards School of Medicine

Marshall University

Huntington, West Virginia

Email: rsingh1492@gmail.com 


\section{ABSTRACT}

Given the difficulty of surgical resection of brain neoplasms located adjacent to vital structures of the brain as well as the challenges posed by the blood-brain-barrier for the efficacy of chemotherapeutic agents, whole brain radiation therapy (WBRT) and stereotactic radiosurgery (SRS) are often turned to for patients with brain metastases as well as primary brain neoplasms. Though radiation therapy may be successful in local control of these tumors, many patients experience treatment-related neurocognitive issues, later in life. In this review, we examine cognitive dysfunction in brain tumor patients following radiation therapy, with an emphasis on the pediatric population. Articles were found using NCBI's PubMed and relevant search terms. We first review the hypotheses regarding the biological mechanisms underlying these neurologic manifestations such as neuroinflammation, extracellular matrix disruption, and inhibition of angiogenesis. Cognitive defects and related effects on health-related quality of life in brain tumor patients treated with radiotherapy are then discussed. We also address novel treatment strategies aimed at minimizing neurocognitive delays such as hippocampal-sparing radiotherapy planning, intensive chemotherapy regimens, and the growing field of proton therapy. Possible molecular therapeutic targets are discussed as well as preclinical studies examining human embryonic and neural stem cell transplantations. Finally, we examine the role of aerobic exercise, multidisciplinary rehabilitation, and other interventions that may help to curb the negative effects of radiotherapy on cognitive development and function.

KEYWORDS: brain tumor, WBRT, SRS, IMRT, cognitive decline, radiotherapy, pediatrics, memory impairment, hippocampus, neural stem cells 


\section{Introduction}

Approximately 210,000 cases of primary and metastatic brain tumors are estimated to be diagnosed each year in the United States. Notably, primary brain tumors are the most common type of solid tumors in children (4,600 primary brain neoplasms are estimated to be diagnosed this year) and are the leading cause of cancer-related deaths in children under the age of 20. (1)

Generally, surgery is the first method of treatment for brain tumor patients. However, tumors deeply-seated within the brain or located near critical structures that control important functions are difficult to remove due to possible iatrogenic neurologic damage. (2) Also, chemotherapy may be utilized for treatment, though the clinical applications of chemotherapy may be limited as a result of both significant side effects and insufficient delivery due to the blood-brain-barrier.

Thus, radiation therapy is often turned to for the treatment of both primary and metastatic brain neoplasms. (4,5) Roughly 200,000 brain tumor patients in the US are treated with some form of radiation each year. (6) Specifically for brain cancers, stereotactic radiosurgery (SRS) and whole brain radiation therapy (WBRT) are often used. SRS delivers a high dose of radiation in one session, whereas WBRT administers ionizing radiation to the entire brain. However, the use of radiation therapy for the treatment of brain tumors is limited by the risk of radiation-induced damage and subsequent functional deficits. This review aims to summarize the neurocognitive effects following radiation therapy in patients with brain tumors with an emphasis on the pediatric population, novel methods of treatment aimed at minimizing cognitive dysfunction, as well as interventions that may be attempted should cognitive delays present.

\section{Methods}

We utilized NCBI's PubMed to identify relevant articles using combinations of search terms such as: brain tumor, cognition, cognitive deficits, radiation therapy, proton therapy, stereotactic radiosurgery, whole brain radiation therapy, intervention, exercise, and pediatric. A total of 94 papers were chosen for inclusion in this review.

\section{Hypotheses Explaining Radiation-Induced Cognitive Dysfunction}

There are many hypotheses that aim to explain the mechanisms underlying cognitive declines following radiation therapy. Most intuitive is the assumption that direct damage and subsequent death of parenchymal cells (oligodendrocytes, neurons, astrocytes, and microglia) contributes to cognitive decline. Damage to oligodendrocytes, which are responsible for myelination of the CNS, has been thought to play a role. Though studies examining rats undergoing fractionated WBRT did find a decrease in the number of oligodendrocytes, no change in the number of myelinated axons or the thickness of myelin sheaths were noted 12 months following treatment. $(7,8)$ Neurons in irradiated rodent brains are found to have altered expression of the immediateearly gene activity-regulated cytoskeleton-associated protein, N-methyl-D-aspartate (NMDA) receptors, glutaminergic transmission, and hippocampal long-term potentiation, all of which are essential to synaptic plasticity and thus cognition. (9) The response of both astrocytes and 
microglia to radiation is thought to contribute to changes in the cellular microenvironment which will be discussed below.

With regards to cognitive decline, radiation damage of the temporal lobe (specifically the hippocampus) likely plays a role. Both memory and learning are influenced by the proliferation of neural stem cells in the hippocampal granule cell layer, which allows for neuron renewal and synapse restructuring. In mature rats, the proliferative potential of this layer has been observed to be greatly reduced following radiation at doses lower than those typically required to injure dysplastic glial cells. (10) However, in vivo studies have demonstrated that older rats experienced cognitive declines following WBRT without impaired hippocampal neurogenesis or demyelination seen in younger rats, suggesting that other mechanisms in non-hippocampal regions are likely to also contribute to neurocognitive issues. (9)

As such, much of the literature has addressed disruption of the integrity of the blood-brainbarrier (BBB) following radiotherapy as a possible explanation for impaired cognition. Increased inflammation following radiation therapy has been implicated. The up regulation of cytokines, which are thought to be expressed by microglia following radiation, and pro-inflammatory transcription factors in the brain are thought to contribute to endothelial cell dysfunction and consequent disruption of the BBB. $(11,12)$ The disruption of the extracellular matrix of the BBB may also be involved as WBRT has been previously documented as altering the expression of matrix metalloproteinases (MMP), leading to collagen IV degradation in both in vitro and in vivo studies. (13) Also, radiation inhibits physiologic angiogenesis in the brain, as evidenced by increased vascular permeability and impaired endothelial cell proliferation in irradiated tissues. (14) Studies have demonstrated that brain samples of rats exhibiting cognitive decline following fractionated WBRT had decreases in vessel density, cerebral blood flow, the number of endothelial cells, and angiogenic factors such as vascular endothelial growth factor (VEGF). $(15,16)$

In addition to disruption of the BBB, the changes mentioned above may also play a role in stem cell lineage. Notably, a study by Monje et al. found that the changes outlined above were observed in the neural microenvironment of radiation-treated mice and resulted in hippocampal progenitor cells differentiating into glial rather than neural cells. ${ }^{17}$ In spite of these findings, there is still a poor understanding of the cellular or molecular mechanisms leading to cognitive dysfunction following radiotherapy. Elucidation of the hypotheses above has led to studies exploring them as potential therapeutic targets that will be discussed shortly.

\section{Cognitive Dysfunction and Related Effects on Quality of Life}

Retrospective studies estimate that neurologic handicaps and impaired cognition are observed in $65 \%$ and $85 \%$, respectively, of patients who were under 3 years of age when they underwent radiotherapy. (18) Many studies have aimed at particular cognitive defects to specific tumor type and location. For example, in children previously treated for pilocytic astrocytoma with normal intelligence prior to diagnosis, all children were noted to have deficits with sustained speech and speed of speech; radiotherapy in these patients further contributed to lower cognitive functioning. Notably, $60 \%$ of patients in this study had difficulty with academics 3 years after treatment. (19) Pediatric patients treated for medulloblastoma were not noted to have visual 
memory deficits as have been noted in other studies, though attention deficits were quite prominent and were correlated with impaired math and reading performance. (20) In comparing intellectual outcomes of children diagnosed with either ependymomas or medulloblastomas and subsequently treated with WBRT, only $10 \%$ of medulloblastoma patients had an IQ above 90 after 10 years as compared to $60 \%$ of ependymoma patients and was hypothesized to be due to cerebral hemisphere radiation (given that this was the only significant difference between the two groups). (21) Notably, declines in both IQ as well as verbal comprehension seems to be dose-dependent, as children with posterior fossa tumors having received $35 \mathrm{~Gy}$ of radiation had lower average scores in both categories as compared to those receiving 0 and $25 \mathrm{~Gy}$. (22) Similar studies have found that compared to age-matched controls, brain tumor patients treated with radiotherapy have significantly lower verbal IQ, processing speed, visual and verbal immediate memory, learning deficits, and selective attention. (23-26) Interestingly, children with brain tumors have also been demonstrated to have significantly poorer working and verbal memory as well as attention deficits even prior to treatment, suggesting that interventions are necessary to mitigate the effects of both the disease process as well as radiotherapy on cognition. (27)

Also of note is the strong correlation between cognitive dysfunction stemming from radiotherapy and a lower quality of life. $(28,29)$ Adults that had been previously diagnosed and treated for brain tumors in childhood have been found to have a 10\%-23\% lower likelihood of attaining a basic education, and this effect was even more marked for female survivors at a $45 \%$ lower probability compared to age-matched controls. A younger age of diagnosis was also significantly associated with a lower likelihood of completing basic education. (30,31) Also, patients that had been previously diagnosed with CNS neoplasms and treated with WBRT had a roughly $10 \%$ lower likelihood of ever being married in their lifetime (this effect is even more pronounced at an estimated 29-38\% lower likelihood for male CNS survivors older than 30 years of age). (32) Similar studies have found that CNS neoplasms survivors often have lower rates of educational attainment, employment, and marriage and consequently a significantly lower quality of life. (33) Survivors' outlook on life is also impaired, as brain tumor survivors that underwent WBRT exhibit low present and expected future life satisfaction as well as higher rates of psychological distress as compared to survivors of other solid tumors.(34) The impaired psychosocial development of brain tumor survivors is also apparent as patients have been shown to be $50 \%$ more likely to experience depression or anxiety and $70 \%$ more likely to exhibit antisocial behaviors, with cranial irradiation being noted as a specific risk factor for both. (35)

\section{Alternative Radiotherapy Treatment Planning and the Promise of Proton Therapy}

Clinical studies have demonstrated that patients receiving higher doses of radiation (and subsequently larger volumes of the brain being treated) have worse prognosis regarding cognitive outcomes. $(36,37)$ Dose-dependent effects in pediatric brain tumor patients have been demonstrated with regard to motor skills/dexterity (hippocampus and temporal lobe), verbal learning (cerebrum), and visual perception (temporal lobe). Though declines relative to agematched controls were noted in a variety of other areas, no association was found between the neurologic structure radiated and the cognitive defect experienced for others tested (such as visuospatial working memory or vocabulary). (38) 
As such, many studies have examined alternative treatment strategies, such as utilizing SRS alone as opposed to WBRT and SRS to minimize the exposure of the brain to radiation. Patients with brain metastases treated with SRS alone experienced declines in Mini Mental Status Examination (MMSE) scores 9 months earlier than those assigned to WBRT and SRS, which suggests that control of tumor growth should be the primary concern for maintaining cognitive function. (39) However, other studies have found that patients treated with SRS alone had a lower incidence of experiencing decline in learning and memory function (24\%) 4 months after treatment than those with WBRT and SRS (52\%); consequently, the authors recommended initial SRS with close clinical monitoring before moving to use of WBRT. (40) Similarly, recent findings from a phase III randomized clinical trial of 213 patients with brain metastases (median follow-up: 7.3 months) found a significantly greater incidence of cognitive decline in patients treated with WBRT + SRS (91.7\%) as compared to those receiving SRS alone (63.5\%), with lower immediate recall, memory, verbal fluency and subsequently quality of life. (41)

The advent of intensity-modulated radiotherapy (IMRT) has also allowed for treatment planning and contouring to avoid radiating hippocampal neural stem cells with WBRT. Previous retrospective studies have demonstrated that WBRT with hippocampal sparing via IMRT reduced doses delivered on a per-fraction basis to the hippocampus by $87 \%$ ( $0.49 \mathrm{~Gy})$ and $81 \%$ $(0.73 \mathrm{~Gy})$ via helical tomotherapy and linear accelerator-based treatments, respectively, with median doses of 5.5 Gy and 7.8 Gy delivered via the same methodologies. (42) Similar studies adopting this approach for adult patients with brain metastases have reported significantly lower rates of memory loss 4 months post-treatment and with no treatment-related decline in quality of life.(43) A prospective phase II trial utilizing hippocampal sparing WBRT reported no significant declines in immediate verbal and nonverbal, executive functioning, or psychomotor speed following treatment, with delayed memory recall being the only neurocognitive function significantly affected. (44)

Another approach is utilizing a lower dose of radiation with adjuvant chemotherapy. Early findings indicate that such an approach for lower to medium risk brain neoplasms can be curative and may be associated with declines in verbal, nonverbal, and full-scale IQ scores but less than those observed with higher doses of radiation alone.(45-48) Other studies examining the role of postoperative chemotherapy to allow for a delay in radiotherapy for a variety of brain neoplasms had similar progression-free survival as compared to standard treatment plans including radiation with minimal observed cognitive dysfunction. $(49,50)$

Most prominent among these trials are the "Head Start" trials, which attempt to use chemotherapy in place of radiotherapy for malignant brain neoplasms. Patients are placed on multiple cycles of chemotherapy for 5 months to reduce the size of the tumor and are then given a single large myeloablatic dose of chemotherapy followed by rescue with autologous hematopoietic stem cells. If no disease is seen on MRI following treatment, then radiotherapy is not used. Studies examining the effectiveness of this approach for supratentorial primitive neuroectodermal tumors (sPNETs), which typically have a poor prognosis, found a survival advantage as well as a significant decline in patients requiring radiation for local control. (51) Similarly, a majority of patients under the age of 3 years old with non-metastatic medulloblastoma treated under this regimen did not require radiation and consequently had both intelligence and quality of life scores within normal ranges, though there was a high toxicity- 
related mortality rate (4/21). (52) Venkatramani et al. also reported the ability to defer radiation for supretentorial ependymomas, though for infratentorial ependymomas such an approach appears to be ineffective. (53) However, studies have previously demonstrated that $40 \%$ of cancer survivors of other sites experienced significant cognitive dysfunction after high dose chemotherapy followed by hematopoietic cell transplantation rescue 1 and 5 years posttreatment; as such, monitoring patients on similar treatment protocols over a long time frame is needed. $(54,55)$

Another novel treatment method that holds promise is proton-beam radiotherapy. Proton therapy is believed to result in greater sparing of healthy tissue and better outcomes due to narrower beams that may allow for a more-targeted delivery of radiation as well as a smaller penetration of tissue beyond the tumor. (56) Given the new nature of this technology, relatively few clinical studies have been completed examining the theoretical advantages of proton therapy for brain neoplasms. Studies that have been done to estimate the clinical benefit of proton therapy based on simulated proton therapy for pediatric medulloblastoma cases found that the mean dose of radiation to the hippocampus could be limited to almost half that of IMRT and consequently lower the risk of cognitive issues later in life.(57) Notably, initial studies have demonstrated that the quality of life of 142 pediatric brain tumor patients 3 years after proton therapy improved to levels similar to healthy age-matched peers, though a comparison was not done comparing such patients to those treated with conventional radiotherapy and thus merits further study.(58)

\section{Results of Potential Therapeutic Targets and Stem Cell Therapies in Preclinical Trials}

Given the various radiation-induced mechanisms previously covered that are hypothesized to interfere with the integrity of the BBB and subsequently lead to cognitive dysfunction, a variety of molecular targets implicated in these mechanisms have been studied. For example, known anti-inflammatory agents such as NSAIDs, peroxisome proliferator-activated receptors (PPAR $\delta$ ) agonists, atorvastatin, and ramipril have been tested following WBRT in mice and rats to reduce microglial activation and subsequent inhibition of hippocampal neurogenesis. However, preclinical studies with the goal of minimizing neuroinflammation have yielded mixed results in preventing cognitive declines.(59-64) Though the possible role that MMPs may have in ECM degradation were previously discussed, presently no work has been done to examine whether this may provide benefit in pre-clinical irradiated brain studies. With regards to angiogenesis, systemic hypoxia following WBRT restored cerebrovascular density and reversed learning and memory impairments. As such, radio-protective drugs have been evaluated in preclinical trials and have been shown to be effective at protection of brain vasculature via preventing loss of endothelial cells and also lowering the proportion of rats brains demonstrating white matter necrosis. $(15,65,66)$ However, studies utilizing any of these approaches have not been attempted in the clinic.

Another field of study that have begun to draw interest are stem cell therapies, given prior studies in mouse models of Alzheimer's disease that have demonstrated improved cognitive functioning following neural stem cell transplantation. A variety of mechanisms such as restoration of brain-derived neutrophic factor (BDNF) levels (involved in neuronal 
differentiation, neurogenesis, and synaptic plasticity necessary for long-term memory) as well as attenuation of inflammation via reduced cytokine expression has been proposed. (67-73)

With regards to brain tumors and radiotherapy, it is believed that transplantation of stem cells can alleviate radiation-induced cognitive dysfunction by increasing the number of neurons via differentiation. Stem cells may also alter the neural microenvironment in the hippocampus to promote synaptic plasticity necessary for memory formation and information processing. Preclinical studies have found that athymic rats that had been both irradiated and had intrahippocampal transplantation of human neural stem cells (hNSCs) expressed activityregulated cytoskeleton-associated protein (Arc, an established marker for detecting active neurons) at similar levels to control levels. Rats undergoing transplantation were found to have consequently improved hippocampal spatial memory and a significantly lower decline in cognitive dysfunction. (74,75) Intrahippocampal nHSCs transplantation has also been demonstrated to provide cognitive benefit lasting 8 months post-radiation (which was not observed following human embryonic stem cell transplantation) and may also attenuate radiation-induced neuroinflammation. $(76,77)$ Notably, transplantations were found to result in the greatest cognitive outcomes if given 4 weeks following radiation as opposed to 2 days or 1 week after radiotherapy, with nearly $40 \%$ of surviving stem cells following a neuronal lineage in the CA1 and CA3 subfields of the hippocampus.(77) Also, human embryonic stem cell-derived oligodendrocytes in irradiated rats have been found to successfully migrate throughout major white matter tracts to participate in functional repair, which resulted in complete recovery of cognitive function to baseline levels. Motor deficits were also found to improve following transplantation of stem cell-derived oligodendrocytes into the cerebellum. (78) However, no significant clinical studies have been documented to our knowledge to date assessing the effectiveness of neural or embryonic stem cell intrahippocampal transplantations in either the pediatric or adult brain tumor populations.

\section{Aerobic Exercise, Multidisciplinary Rehabilitation, and Other Interventions}

In addition to the treatment options discussed earlier, many other interventions such as cardiovascular exercise may be helpful in improving cognitive functioning. Preclinical models have aimed at better elucidating whether exercise does attenuate radiation-induced cognitive dysfunction and the molecular mechanisms by which it may do so. Studies in mice have demonstrated that voluntary running starting 1 month following WBRT prevented marked declines in spacial memory, with possible mechanisms including partial neuron regeneration in the dentate gyrus and increased hippocampal expression of VEGF and IGF-1.(79) Similar studies in irradiated rats have demonstrated that 3 weeks of forced running attenuated radiationinduced declines in hippocampal neurons and expression of BDNF and was correlated with improved behavioral performance. (80) Declines in BDNF have been implicated in playing a large role in radiation-induced cognitive dysfunction, as other studies in rats subject to $30 \mathrm{~Gy}$ of WBRT have demonstrated significant declines in BDNF gene transcription via an epigenetic mechanism. Notably, a decrease in histone-deacetylase 1 (HDAC1) - dependent H3 acetylation was noted at BDNF gene promoters, which was reversed following administration of an HDAC inhibitor with consequent improved hippocampal neurogenesis.(81) As discussed earlier, BDNF plays a key role in memory formation via promotion of neuronal differentiation and neurogenesis, and attenuation of declines of BDNF in Alzheimer's disease models and other 
neurocognitive disorders have been associated with improved learning and memory in preclinical models.

Surprisingly, there have been a limited number of studies examining the effectiveness of exercise and other cognitive rehabilitations for both pediatric and adult brain tumor populations. Studies utilizing fMRIs for pediatric posterior fossa cancer survivors have demonstrated that declines in executive function, notably working memory, can be improved via cardiorespiratory exercise. (82) However, levels of exercise among pediatric brain tumor survivors are reported to be greater than one standard deviation below age-matched peers, and as such interventions may be necessary to promote activity among such patients to realize potential cognitive benefits from exercise. (83-85) Furthermore, cognitive rehabilitation in glioma patients has been demonstrated to lead to improved verbal memory and attention with less mental fatigue 6 months after intervention as compared to control subjects.(86) Four-week conventional rehabilitation programs (including physical and neuromuscular electrical stimulation as well as aerobic exercise) for brain tumor patients have noted similar success with significant rises in MMSE scores as well as visual attention, selective, and auditory attention.(87) Similarly, Gehring et al. reported significantly higher attention and visual memory scores among 140 adult survivors of low-grade and anaplastic astrocytoma patients 6-months following cognitive rehabilitation with less mental fatigue reported by patients undergoing rehabilitation. (88) Also, a cohort of 11 adult patients diagnosed with higher-grade gliomas (i.e. glioblastoma multiforme) with Karnofsky performance scores of $80 \%$ or higher participating in weekly neurocognitive rehabilitation sessions for 3 months exhibited higher mean attention, verbal, and memory scores, though only verbal scores exhibited significant increases from baseline.(89) A larger controlled clinical trial of over 100 adult glioma survivors participating in a multidisciplinary rehabilitation program found significant increases in self-care, locomotion, mobility, communication, and psychosocial scores at 3 month follow-up among the patients participating in the program compared to control, though only gains in cognition and communication were noted at 6 month followup.(90)

However, it is important to note that systemic reviews of multidisciplinary rehabilitation in brain tumor patients have found a "low-level" quality of evidence supporting rehabilitation for longterm cognitive improvement. Also, no studies thus far have clearly demonstrated significant improvements in health-related quality of life following such interventions. As such, studies examining the effect of exercise and cognitive rehabilitation on longer-term cognitive performance are warranted to better define the optimal setting, type, intensity, and duration of neurocognitive interventions, especially given the paucity of literature in the pediatric brain tumor population. (91)

A variety of other alternative interventions have been attempted to prevent cognitive declines. Notably, Meyers et al. found that half of brain tumor patients who took the CNS stimulant methylphenidate before and during radiotherapy experienced cognitive function increases despite neurologic injury demonstrated on MRI. (92) However, more recent studies have found prophylactic methylphenidate does not result in a significant rise in MMSE scores or increases in quality of life. (93) Memantine, an NMDA antagonist commonly used in Alzheimer's, and Ginkgo biloba (also used in Alzheimer's to disease to improve cognitive deterioration) has been found to significantly prolong the time until onset of declining executive function and processing 
speed for patients with brain metastases treated with WBRT of up to 24 weeks with some improvements in quality of life. $(94,95)$

\section{Conclusion}

While great advances have been made in the treatment of cancer, cognitive disabilities may persist in patients (particularly children) with brain tumors for which radiotherapy remains a mainstay of treatment. Current research efforts aim to reduce neurotoxicity and associated cognitive dysfunction of treatment by alternative treatment planning such as larger doses of chemotherapy or avoiding vital structures such as the hippocampus during radiation planning via IMRT. It is a worthwhile endeavor to further elucidate the mechanisms by which radiation impairs cognitive abilities to allow for cellular and molecular pathways to be targeted in the future. Other innovative treatment modalities, namely proton therapy and intrahippocampal stem cell transplantations, may also have a large role to play in times to come given promising early findings with the objective of improving quality of life for cancer survivors. 


\section{References}

1. American Brain Tumor Association. "Brain Tumor Statistics". http://www.abta.org/about-us/news/braintumor-statistics . Accessed November 232015.

2 Cohadon F. Indications for surgery in the management of gliomas. Adv Tech Stand Neurosurg 1990;17:189-234.

3 Buckner JC, Brown PD, O'Neill BP, Meyer FB, Wetmore CJ, Uhm JH. Central nervous system tumors. Mayo Clin Proc. 2007 Oct;82(10):1271-86.

4 Khuntia D, Brown P, Li J, Mehta MP. Whole-brain radiotherapy in the management of brain metastasis. J. Clin. Oncol. 2006;24:1295-1304. doi: 10.1200/JCO.2005.04.6185.

5 Kantor G, Laprie A, Huchet A, Loiseau H, Dejean C, Mazeron JJ. Radiation therapy for glial tumors: technical aspects and clinical indications. Cancer Radiother. (2008);12:687-694. doi: 10.1016/j.canrad.2008.09.004.

6. Ostrom, QT, Gittleman, G, Fulop, J, et al. CBTRUS Statistical Report: Primary Brain and Central Nervous System Tumors Diagnosed in the United States in 2008-2012, Neuro Oncol (2015) 17 (suppl 4): iv1-iv62 doi: 10.1093/neuonc/nov189.

7. Kurita H, Kawahara N, Asai A, Ueki K, Shin M, Kirino T. Radiation-induced apoptosis of oligodendrocytes in the adult rat brain. Neurol Res. 2001 Dec; 23(8):869-74.

8. Shi L, Linville MC, Iversen E, Molina DP, Yester J, Wheeler KT, Robbins ME, Brunso-Bechtold JK. Maintenance of white matter integrity in a rat model of radiation-induced cognitive impairment. J Neurol Sci. 2009 Oct 15; 285(1-2):178-84.

9. Greene-Schloesser D, Robbins ME, Peiffer AM, Shaw EG, Wheeler KT, Chan MD. Radiation-induced brain injury: A review. Front Oncol. 2012 Jul 19;2:73. doi: 10.3389/fonc.2012.00073. eCollection 2012.

10 Monje ML, Palmer T. Radiation injury and neurogenesis. Curr Opin Neurol. 2003 Apr;16(2): 129-34.

11 Hong J. H., Chiang C. S., Campbell I. L., Sun J. R., Withers H. R., McBride W. H. Induction of acute phase gene ex-pression by brain irradiation. Int. J. Radiat. Oncol. Biol. Phys. (1995);33:619-626. doi: 10.1016/0360-3016(95)00279-8.

12 Gaber MW, Sabek OM, Fukatsu K, Wilcox HG, Kiani MF, Merchant TE. Differences in ICAM-1 and TNF-alpha expression between large single fraction and fractionated irradiation in mouse brain. Int J Radiat Biol. 2003 May; 79(5):359-66.

Lee WH, Warrington JP, Sonntag WE, Lee YW. Irradiation alters MMP-2/TIMP-2 system and collagen type IV degradation in brain. Int J Radiat Oncol Biol Phys. 2012 Apr 1; 82(5):1559-66.

14 Baker DG, Krochak RJ. The response of the microvascular system to radiation: a review. Cancer Invest. 1989; 7(3):287-94.

15 Warrington JP, Csiszar A, Mitschelen M, Lee YW, Sonntag WE. Whole brain radiation-induced impairments in learning and memory are time-sensitive and reversible by systemic hypoxia. PLoS One. 2012; 7(1):e30444.

Lee WH, Cho HJ, Sonntag WE, Lee YW. Radiation attenuates physiological angiogenesis by differential expression of VEGF, Ang-1, tie-2 and Ang-2 in rat brain. Radiat Res. 2011 Dec; 176(6):753-60.

17 Monje ML, Mizumatsu S, Fike JR, Palmer TD. Irradiation induces neural precursor-cell dysfunction. Nat Med. 2002 Sep;8(9):955-62. Epub 2002 Aug 5.

Suc E, Kalifa C, Brauner R, Habrand JL, Terrier-Lacombe MJ, Vassal G, Lemerle J. Brain tumours under the age of three. The price of survival. A retrospective study of 20 long-term survivors. Acta Neurochir (Wien). 1990;106(3-4):93-8. 

Cognitive deficits and predictors 3 years after diagnosis of a pilocytic astrocytoma in childhood. J Clin Oncol. 2009 Jul 20;27(21):3526-32. doi: 10.1200/JCO.2008.19.6303. Epub 2009 May 11.

Reeves CB, Palmer SL, Reddick WE, Merchant TE, Buchanan GM, Gajjar A, Mulhern RK. Attention and memory functioning among pediatric patients with medulloblastoma. J Pediatr Psychol. 2006 Apr;31(3):272-80. Epub 2005 Mar 23.

Hoppe-Hirsch E, Brunet L, Laroussinie F, Cinalli G, Pierre-Kahn A, Rénier D, Sainte-Rose C, Hirsch JF. Intellectual outcome in children with malignant tumors of the posterior fossa: influence of the field of irradiation and quality of surgery. Childs Nerv Syst. 1995 Jun;11(6):340-5; discussion 345-6.

Shortman RI, Lowis SP, Penn A, McCarter RJ, Hunt LP, Brown CC, Stevens MC, Curran AL, Sharples PM. Cognitive function in children with brain tumors in the first year after diagnosis compared to healthy matched controls. Pediatr Blood Cancer. 2014 Mar;61(3):464-72. doi: 10.1002/pbc.24746. Epub 2013 Aug 29.

Duffner PK, Cohen ME, Thomas P. Late effects of treatment on the intelligence of children with posterior fossa tumors. Cancer. 1983 Jan 15;51(2):233-7.

Margelisch K, Studer M, Ritter BC, Steinlin M, Leibundgut K, Heinks T. Cognitive dysfunction in children with brain tumors at diagnosis. Pediatr Blood Cancer. 2015 Oct;62(10):1805-12. doi: 10.1002/pbc.25596. Epub 2015 Jun 5.

Palmer SL, Goloubeva O, Reddick WE, Glass JO, Gajjar A, Kun L, Merchant TE, Mulhern RK. Patterns of intellectual development among survivors of pediatric medulloblastoma: a longitudinal analysis. J Clin Oncol. 2001 Apr 15;19(8):2302-8.

Copeland DR, deMoor C, Moore BD 3rd, Ater JL. Neurocognitive development of children after a cerebellar tumor in infancy: A longitudinal study. J Clin Oncol. 1999 Nov;17(11):3476-86.

Grill J, Renaux VK, Bulteau C, Viguier D, Levy-Piebois C, Sainte-Rose C, Dellatolas G, Raquin MA, Jambaqué I, Kalifa C. Long-term intellectual outcome in children with posterior fossa tumors according to radiation doses and volumes. Int J Radiat Oncol Biol Phys. 1999 Aug 1;45(1):137-45.

Mulhern RK. Correlation of the Health Utilities Index Mark 2 cognition scale and neuropsychological functioning among survivors of childhood medulloblastoma. Int J Cancer Suppl. 1999;12:91-94.

Ribi K, Relly C, Landolt MA, et al. Outcome of medulloblastoma in children: Long-term complications and quality of life. Neuropediatrics. 2005; 36:357-365.

Koch SV, Kejs AM, Engholm G, Johansen C, Schmiegelow K. Educational attainment among survivors of childhood cancer: a population-based cohort study in Denmark. Br J Cancer. 2004 Aug 31;91(5):923-8.

Lancashire ER, Frobisher C, Reulen RC, Winter DL, Glaser A, Hawkins MM. Educational attainment among adult survivors of childhood cancer in Great Britain: a population-based cohort study. J Natl Cancer Inst. 2010 Feb 24;102(4):254-70. doi: 10.1093/jnci/djp498. Epub 2010 Jan 27.

Frobisher C, Lancashire ER, Winter DL, Jenkinson HC, Hawkins MM; British Childhood Cancer Survivor Study. Long-term population-based marriage rates among adult survivors of childhood cancer in Britain. Int J Cancer. 2007 Aug 15;121(4):846-55.

Pastore G, Mosso ML, Magnani C, Luzzatto L, Bianchi M, Terracini B. Physical impairment and social life goals among adult long-term survivors of childhood cancer: a population-based study from the childhood cancer registry of Piedmont, Italy. Tumori. 2001 Nov-Dec;87(6):372-8.

Zeltzer LK, Recklitis C, Buchbinder D, Zebrack B, Casillas J, Tsao JC, Lu Q, Krull K. Psychological status in childhood cancer survivors: a report from the Childhood Cancer Survivor Study. J Clin Oncol. 2009 May 10;27(14):2396-404. doi: 10.1200/JCO.2008.21.1433. Epub 2009 Mar 2.

Schultz KA, Ness KK, Whitton J, Recklitis C, Zebrack B, Robison LL, Zeltzer L, Mertens AC. Behavioral and social outcomes in adolescent survivors of childhood cancer: a report from the childhood cancer survivor study. J Clin Oncol. 2007 Aug 20;25(24):3649-56. 

radiation dosimetry to predict cognitive outcomes in pediatric patients with CNS embryonal tumors including medulloblastoma. Int J Radiat Oncol Biol Phys. 2006 May 1;65(1):210-21. Epub 2006 Feb 10.

Mulhern RK, Kepner JL, Thomas PR, Armstrong FD, Friedman HS, Kun LE. Neuropsychologic functioning of survivors of childhood medulloblastoma randomized to receive conventional or reduceddose craniospinal irradiation: a Pediatric Oncology Group study. J Clin Oncol. 1998 May;16(5):1723-8.

Redmond KJ, Mahone EM, Terezakis S, Ishaq O, Ford E, McNutt T, Kleinberg L, Cohen KJ, Wharam M, Horska A. Association between radiation dose to neuronal progenitor cell niches and temporal lobes and performance on neuropsychological testing in children: a prospective study. Neuro Oncol. 2013 Mar;15(3):360-9. doi: 10.1093/neuonc/nos303. Epub 2013 Jan 14.

Aoyama H, Tago M, Kato N, Toyoda T, Kenjyo M, Hirota S, Shioura H, Inomata T, Kunieda E, Hayakawa K, Nakagawa K, Kobashi G, Shirato H. Neurocognitive function of patients with brain metastasis who received either whole brain radiotherapy plus stereotactic radiosurgery or radiosurgery alone. Int J Radiat Oncol Biol Phys. 2007 Aug 1;68(5):1388-95.

Chang EL, Wefel JS, Hess KR, Allen PK, Lang FF, Kornguth DG, Arbuckle RB, Swint JM, Shiu AS, Maor $\mathrm{MH}$, Meyers CA. Neurocognition in patients with brain metastases treated with radiosurgery or radiosurgery plus whole-brain irradiation: a randomised controlled trial. Lancet Oncol. 2009 Nov;10(11):1037-44. doi: 10.1016/S1470-2045(09)70263-3. Epub 2009 Oct 2.

Brown PD, Asher AL, Farace E, et al. NCCTG N0574 (Alliance): A phase III randomized trial of whole brain radiation therapy (WBRT) in addition to radiosurgery (SRS) in patients with 1 to 3 brain metastases. J Clin Oncol 33, 2015 (suppl; abstr LBA4) accelerator-based intensity-modulated radiotherapy. Int J Radiat Oncol Biol Phys. 2010 Nov 15;78(4):1244-52. doi: 10.1016/j.ijrobp.2010.01.039.

Lin SY, Yang CC, Wu YM, Tseng CK, Wei KC, Chu YC, Hsieh HY, Wu TH, Pai PC, Hsu PW, Chuang CC. Evaluating the impact of hippocampal sparing during whole brain radiotherapy on neurocognitive functions: A preliminary report of a prospective phase II study. Biomed J. 2015 Sep-Oct;38(5):439-49. doi: 10.4103/2319-4170.157440.

Gondi V, Pugh SL, Tome WA, Caine C, Corn B, Kanner A, Rowley H, Kundapur V, DeNittis A, Greenspoon JN, Konski AA, Bauman GS, Shah S, Shi W, Wendland M, Kachnic L, Mehta MP. Preservation of memory with conformal avoidance of the hippocampal neural stem-cell compartment during whole-brain radiotherapy for brain metastases (RTOG 0933): a phase II multi-institutional trial. J Clin Oncol. 2014 Dec 1;32(34):3810-6. doi: 10.1200/JCO.2014.57.2909. Epub 2014 Oct 27.

Goldwein JW, Radcliffe J, Johnson J, Moshang T, Packer RJ, Sutton LN, Rorke LB, D'Angio GJ. Updated results of a pilot study of low dose craniospinal irradiation plus chemotherapy for children under five with cerebellar primitive neuroectodermal tumors (medulloblastoma). Int J Radiat Oncol Biol Phys. 1996 Mar 1;34(4):899-904.

Allen JC, Donahue B, DaRosso R, Nirenberg A. Hyperfractionated craniospinal radiotherapy and adjuvant chemotherapy for children with newly diagnosed medulloblastoma and other primitive neuroectodermal tumors. Int J Radiat Oncol Biol Phys. 1996 Dec 1;36(5):1155-61.

Duffner PK, Horowitz ME, Krischer JP, Friedman HS, Burger PC, Cohen ME, Sanford RA, Mulhern RK, James HE, Freeman CR, et al. Postoperative chemotherapy and delayed radiation in children less than three years of age with malignant brain tumors. N Engl J Med. 1993 Jun 17;328(24):1725-31.

Ris MD, Packer R, Goldwein J, Jones-Wallace D, Boyett JM. Intellectual outcome after reduced-dose radiation therapy plus adjuvant chemotherapy for medulloblastoma: a Children's Cancer Group study. J Clin Oncol. 2001 Aug 1;19(15):3470-6. 
Ellison DW, Machin D; Children's Cancer and Leukaemia Group (formerly UKCCSG) Brain Tumour Committee. Primary postoperative chemotherapy without radiotherapy for intracranial ependymoma in children: the UKCCSG/SIOP prospective study. Lancet Oncol. 2007 Aug;8(8):696-705.

50 Grundy RG, Wilne SH, Robinson KJ, Ironside JW, Cox T, Chong WK, Michalski A, Campbell RH, Bailey CC, Thorp N, Pizer B, Punt J, Walker DA, Ellison DW, Machin D; Children's Cancer and Leukaemia Group Brain Tumour Committee. Primary postoperative chemotherapy without radiotherapy for treatment of brain tumours other than ependymoma in children under 3 years: results of the first UKCCSG/SIOP CNS 9204 trial. Eur J Cancer. 2010 Jan;46(1):120-33. doi: 10.1016/j.ejca.2009.09.013.

51 Fangusaro J, Finlay J, Sposto R, Ji L, Saly M, Zacharoulis S, Asgharzadeh S, Abromowitch M, Olshefski R, Halpern S, Dubowy R, Comito M, Diez B, Kellie S, Hukin J, Rosenblum M, Dunkel I, Miller DC, Allen J, Gardner S. Intensive chemotherapy followed by consolidative myeloablative chemotherapy with autologous hematopoietic cell rescue (AuHCR) in young children with newly diagnosed supratentorial primitive neuroectodermal tumors (sPNETs): report of the Head Start I and II experience. Pediatr Blood Cancer. 2008 Feb;50(2):312-8.

Dhall G, Grodman H, Ji L, Sands S, Gardner S, Dunkel IJ, McCowage GB, Diez B, Allen JC, Gopalan A, Cornelius AS, Termuhlen A, Abromowitch M, Sposto R, Finlay JL. Outcome of children less than three years old at diagnosis with non-metastatic medulloblastoma treated with chemotherapy on the "Head Start" I and II protocols. Pediatr Blood Cancer. 2008 Jun;50(6):1169-75. doi: 10.1002/pbc.21525.

53 Venkatramani R, Ji L, Lasky J, Haley K, Judkins A, Zhou S, Sposto R, Olshefski R, Garvin J, Tekautz T, Kennedy G, Rassekh SR, Moore T, Gardner S, Allen J, Shore R, Moertel C, Atlas M, Dhall G, Finlay J. Outcome of infants and young children with newly diagnosed ependymoma treated on the "Head Start" III prospective clinical trial. J Neurooncol. 2013 Jun;113(2):285-91. doi: 10.1007/s11060-013-1111-9. Epub 2013 Mar 19.

54 Syrjala KL, Artherholt SB, Kurland BF, Langer SL, Roth-Roemer S, Elrod JB, Dikmen S. Prospective neurocognitive function over 5 years after allogeneic hematopoietic cell transplantation for cancer survivors compared with matched controls at 5 years. J Clin Oncol. 2011 Jun 10;29(17):2397-404. doi: 10.1200/JCO.2010.33.9119. Epub 2011 May 2.

55 Scherwath A, Schirmer L, Kruse M, Ernst G, Eder M, Dinkel A, Kunze S, Balck F, Bornhäuser M, Ehninger G, Dolan K, Gramatzki M, Kolb HJ, Heußner P, Wilhelm H, Beelen DW, Schulz-Kindermann F, Zander AR, Koch U, Mehnert A. Cognitive functioning in allogeneic hematopoietic stem cell transplantation recipients and its medical correlates: a prospective multicenter study. Psychooncology. 2013 Jul;22(7):1509-16. doi: 10.1002/pon.3159. Epub 2012 Sep 4.

56 Weber DC, Ares C, Lomax AJ, et al. Radiation therapy planning with photons and protons for early and advanced breast cancer: An overview. Radiat Oncol. 2006; 1:22

57 Blomstrand M, Brodin NP, Munck Af Rosenschöld P, Vogelius IR, Sánchez Merino G, Kiil-Berthlesen A, Blomgren K, Lannering B, Bentzen SM, Björk-Eriksson T. Estimated clinical benefit of protecting neurogenesis in the developing brain during radiation therapy for pediatric medulloblastoma. Neuro Oncol. 2012 Jul;14(7):882-9. doi: 10.1093/neuonc/nos120. Epub 2012 May 17.

58 Kuhlthau KA, Pulsifer MB, Yeap BY, et al. (2012) Prospective study of health-related quality of life for children with brain tumors treated with proton radiotherapy. J Clin Oncol 30:2079-2086

Ramanan S, Kooshki M, Zhao W, Hsu FC, Riddle DR, Robbins ME. The PPARalpha agonist fenofibrate preserves hippocampal neurogenesis and inhibits microglial activation after whole-brain irradiation. Int $\mathbf{J}$ Radiat Oncol Biol Phys. 2009 Nov 1;75(3):870-7. doi: 10.1016/j.ijrobp.2009.06.059.

60 Schnegg CI, Greene-Schloesser D, Kooshki M, Payne VS, Hsu FC, Robbins ME. The PPAR $\delta$ agonist GW0742 inhibits neuroinflammation, but does not restore neurogenesis or prevent early delayed hippocampal-dependent cognitive impairment after whole-brain irradiation. Free Radic Biol Med. 2013 Aug;61:1-9. doi: 10.1016/j.freeradbiomed.2013.03.002. Epub 2013 Mar 14.

61 Jenrow KA, Brown SL, Lapanowski K, Naei H, Kolozsvary A, Kim JH. Selective inhibition of microgliamediated neuroinflammation mitigates radiation-induced cognitive impairment. Radiat Res. 2013 May;179(5):549-56. doi: 10.1667/RR3026.1. Epub 2013 Apr 5. 

mitigate radiation-induced impairment of dentate gyrus neurogenesis. J Neurooncol. 2011 Feb;101(3):44956. doi: 10.1007/s11060-010-0282-x. Epub 2010 Jul 9.

Jenrow KA, Brown SL, Liu J, Kolozsvary A, Lapanowski K, Kim JH. Ramipril mitigates radiation-induced impairment of neurogenesis in the rat dentate gyrus. Radiat Oncol. 2010 Feb 1;5:6. doi: 10.1186/1748717X-5-6.

Monje ML, Toda H, Palmer TD. Inflammatory blockade restores adult hippocampal neurogenesis. Science. 2003 Dec 5;302(5651):1760-5. Epub 2003 Nov 13.

Plotnikova ED, Levitman MK, Shaposhnikova VV, Koshevoj JV, Eidus LK. Protection of microvasculature in rat brain against late radiation injury by gammaphos. Int J Radiat Oncol Biol Phys. 1988 Nov; 15(5):1197-201.

Lyubimova N, Hopewell JW. Experimental evidence to support the hypothesis that damage to vascular endothelium plays the primary role in the development of late radiation-induced CNS injury. Br J Radiol. 2004 Jun; 77(918):488-92.

Kim JA, Ha S, Shin KY, Kim S, Lee KJ, Chong YH, Chang KA, Suh YH. Neural stem cell transplantation at critical period improves learning and memory through restoring synaptic impairment in Alzheimer's disease mouse model. Cell Death Dis. 2015 Jun 18;6:e1789. doi: 10.1038/cddis.2015.138.

Goldberg NR, Caesar J, Park A, Sedgh S, Finogenov G, Masliah E, Davis J, Blurton-Jones M. Neural Stem Cells Rescue Cognitive and Motor Dysfunction in a Transgenic Model of Dementia with Lewy Bodies through a BDNF-Dependent Mechanism. Stem Cell Reports. 2015 Nov 10;5(5):791-804. doi: 10.1016/j.stemcr.2015.09.008. Epub 2015 Oct 17.

Zhang Q, Wu HH, Wang Y, Gu GJ, Zhang W, Xia R. Neural stem cell transplantation decreases neuroinflammation in a transgenic mouse model of Alzheimer's disease. J Neurochem. 2015 Nov 3. doi: 10.1111/jnc.13413. [Epub ahead of print]

Lee IS, Jung K, Kim IS, Lee H, Kim M, Yun S, Hwang K, Shin JE, Park KI. Human neural stem cells alleviate Alzheimer-like pathology in a mouse model. Mol Neurodegener. 2015 Aug 21;10:38. doi: 10.1186/s13024-015-0035-6.

Bekinschtein P, Cammarota M, Katche C, Slipczuk L, Rossato JI, Goldin A, Izquierdo I, Medina JH. BDNF is essential to promote persistence of long-term memory storage. Proc Natl Acad Sci U S A. 2008 Feb 19;105(7):2711-6. doi: 10.1073/pnas.0711863105. Epub 2008 Feb 8.

Bekinschtein P, Cammarota M, Igaz LM, Bevilaqua LR, Izquierdo I, Medina JH. Persistence of long-term memory storage requires a late protein synthesis- and BDNF- dependent phase in the hippocampus. Neuron. 2007 Jan 18;53(2):261-77.

Alonso M, Vianna MR, Depino AM, Mello e Souza T, Pereira P, Szapiro G, Viola H, Pitossi F, Izquierdo I, Medina JH. BDNF-triggered events in the rat hippocampus are required for both short- and long-term memory formation. Hippocampus. 2002;12(4):551-60.

Acharya MM, Rosi S, Jopson T, Limoli CL. Human neural stem cell transplantation provides long-term restoration of neuronal plasticity in the irradiated hippocampus. Cell Transplant. 2015;24(4):691-702. doi: 10.3727/096368914X684600. Epub 2014 Oct 6.

Acharya MM, Christie LA, Hazel TG, Johe KK, Limoli CL. Transplantation of human fetal-derived neural stem cells improves cognitive function following cranial irradiation. Cell Transplant. 2014;23(10):1255-66. doi: 10.3727/096368913X670200. Epub 2013 Jul 17.

Acharya MM, Martirosian V, Christie LA, Limoli CL. Long-term cognitive effects of human stem cell transplantation in the irradiated brain. Int J Radiat Biol. 2014 Sep;90(9):816-20. doi: 10.3109/09553002.2014.927934. Epub 2014 Jun 25. 
ameliorate radiation-induced cognitive impairment. Stem Cells Transl Med. 2015 Jan;4(1):74-83. doi: 10.5966/sctm.2014-0063. Epub 2014 Nov 12.

Piao J, Major T, Auyeung G, Policarpio E, Menon J, Droms L, Gutin P, Uryu K, Tchieu J, Soulet D, Tabar V. Human embryonic stem cell-derived oligodendrocyte progenitors remyelinate the brain and rescue behavioral deficits following radiation. Cell Stem Cell. 2015 Feb 5;16(2):198-210. doi: 10.1016/j.stem.2015.01.004.

Wong-Goodrich SJ, Pfau ML, Flores CT, Fraser JA, Williams CL, Jones LW. Voluntary running prevents progressive memory decline and increases adult hippocampal neurogenesis and growth factor expression after whole-brain irradiation. Cancer Res. 2010 Nov 15;70(22):9329-38. doi: 10.1158/0008-5472.CAN-101854. Epub 2010 Sep 30.

Ji JF, Ji SJ, Sun R, Li K, Zhang Y, Zhang LY, Tian Y. Forced running exercise attenuates hippocampal neurogenesis impairment and the neurocognitive deficits induced by whole-brain irradiation via the BDNFmediated pathway. Biochem Biophys Res Commun. 2014 Jan 10;443(2):646-51. doi: 10.1016/j.bbrc.2013.12.031. Epub 2013 Dec 11.

81 Ji S, Tian Y, Lu Y, Sun R, Ji J, Zhang L, Duan S. Irradiation-induced hippocampal neurogenesis impairment is associated with epigenetic regulation of bdnf gene transcription. Brain Res. 2014 Aug 19;1577:77-88. doi: 10.1016/j.brainres.2014.06.035. Epub 2014 Jul 11.

Wolfe KR, Madan-Swain A, Hunter GR, Reddy AT, Baños J, Kana RK. An fMRI investigation of working memory and its relationship with cardiorespiratory fitness in pediatric posterior fossa tumor survivors who received cranial radiation therapy. Pediatr Blood Cancer. 2013 Apr;60(4):669-75. doi: 10.1002/pbc.24331. Epub 2012 Oct 5.

Wolfe KR, Hunter GR, Madan-Swain A, Reddy AT, Baños J, Kana RK. Cardiorespiratory fitness in survivors of pediatric posterior fossa tumor. J Pediatr Hematol Oncol. 2012 Aug;34(6):e222-7. doi: 10.1097/MPH.0b013e3182661996.

Piscione PJ, Bouffet E, Mabbott DJ, Shams I, Kulkarni AV. Physical functioning in pediatric survivors of childhood posterior fossa brain tumors. Neuro Oncol. 2014 Jan;16(1):147-55. doi: 10.1093/neuonc/not138. Epub 2013 Dec 4.

Winter C, Müller C, Hoffmann C, Boos J, Rosenbaum D. Physical activity and childhood cancer. Pediatr Blood Cancer. 2010 Apr; 54(4):501-10.

Gehring K, Sitskoorn MM, Gundy CM, Sikkes SA, Klein M, Postma TJ, van den Bent MJ, Beute GN, Enting RH, Kappelle AC, Boogerd W, Veninga T, Twijnstra A, Boerman DH, Taphoorn MJ, Aaronson NK. Cognitive rehabilitation in patients with gliomas: a randomized, controlled trial. J Clin Oncol. 2009 Aug 1;27(22):3712-22. doi: 10.1200/JCO.2008.20.5765. Epub 2009 May 26.

Han EY, Chun MH, Kim BR, Kim HJ. Functional Improvement After 4-Week Rehabilitation Therapy and Effects of Attention Deficit in Brain Tumor Patients: Comparison With Subacute Stroke Patients. Ann Rehabil Med. 2015 Aug;39(4):560-9. doi: 10.5535/arm.2015.39.4.560. Epub 2015 Aug 25.

Gehring K, Sitskoorn MM, Gundy CM, Sikkes SA, Klein M, Postma TJ, van den Bent MJ, Beute GN, Enting RH, Kappelle AC, Boogerd W, Veninga T, Twijnstra A, Boerman DH, Taphoorn MJ, Aaronson NK. Cognitive rehabilitation in patients with gliomas: a randomized, controlled trial. J Clin Oncol. 2009 Aug 1;27(22):3712-22. doi: 10.1200/JCO.2008.20.5765. Epub 2009 May 26.

Hassler MR, Elandt K, Preusser M, Lehrner J, Binder P, Dieckmann K, Rottenfusser A, Marosi C. Neurocognitive training in patients with high-grade glioma: a pilot study. J Neurooncol. 2010 Mar;97(1):109-15. doi: 10.1007/s11060-009-0006-2. Epub 2009 Sep 10.

Khan F, Amatya B, Drummond K, Galea M. Effectiveness of integrated multidisciplinary rehabilitation in primary brain cancer survivors in an Australian community cohort: a controlled clinical trial. J Rehabil Med. 2014 Sep;46(8):754-60. doi: 10.2340/16501977-1840.

Khan F, Amatya B, Ng L, Drummond K, Galea M. Multidisciplinary rehabilitation after primary brain tumour treatment. Cochrane Database Syst Rev. 2015 Aug 23;8:CD009509. doi:

10.1002/14651858.CD009509.pub3. 
92 Meyers CA, Weitzner MA, Valentine AD, Levin VA. Methylphenidate therapy improves cognition, mood, and function of brain tumor patients. J Clin Oncol. 1998 Jul;16(7):2522-7.

93 Butler JM Jr, Case LD, Atkins J, Frizzell B, Sanders G, Griffin P, Lesser G, McMullen K, McQuellon R, Naughton M, Rapp S, Stieber V, Shaw EG. A phase III, double-blind, placebo-controlled prospective randomized clinical trial of d-threo-methylphenidate $\mathrm{HCl}$ in brain tumor patients receiving radiation therapy. Int J Radiat Oncol Biol Phys. 2007 Dec 1;69(5):1496-501. Epub 2007 Sep 14.

94 Brown PD, Pugh S, Laack NN, Wefel JS, Khuntia D, Meyers C, Choucair A, Fox S, Suh JH, Roberge D, Kavadi V, Bentzen SM, Mehta MP, Watkins-Bruner D; Radiation Therapy Oncology Group (RTOG).

Memantine for the prevention of cognitive dysfunction in patients receiving whole-brain radiotherapy: a randomized, double-blind, placebo-controlled trial. Neuro Oncol. 2013 Oct;15(10):1429-37. doi: 10.1093/neuonc/not114. Epub 2013 Aug 16.

95 Attia A, Rapp SR, Case LD, D'Agostino R, Lesser G, Naughton M, McMullen K, Rosdhal R, Shaw EG. Phase II study of Ginkgo biloba in irradiated brain tumor patients: effect on cognitive function, quality of life, and mood. J Neurooncol. 2012 Sep;109(2):357-63. doi: 10.1007/s11060-012-0901-9. Epub 2012 Jun 15. 